\title{
Differential Regulation of Basal and Cyclic Adenosine 3',5' - Monophosphate-Induced Somatostatin Gene Transcription in Neural Cells by DNA Control Elements That Bind Homeodomain Proteins
}

\author{
Petra T. Schwartz and Mario Vallejo \\ Reproductive Endocrine Unit \\ Massachusetts General Hospital \\ Harvard Medical School \\ Boston, Massachusetts 02114
}

A number of genes encoding neuropeptides are expressed in the peripheral and central nervous systems, in different endocrine organs, and in specialized cells distributed along the gastrointestinal tract. Whether expression of the same neuropeptide gene in different tissues is regulated by similar transcriptional mechanisms or by mechanisms that differ in a cell-specific manner remains unclear. We report on promoter studies on the regulation of the somatostatin gene in immortalized neural precursor cells derived from developing rat forebrain. Expression of the somatostatin gene in these cells was determined by RT-PCR/Southern blot analysis, by immunocytochemistry, and by RIA. We show that in cerebrocortical and hippocampal cells, expression of the somatostatin gene is regulated by several negative and positive DNA cis-regulatory elements located throughout the promoter region. The somatostatin cAMPresponse element appears to play a prominent role in neural somatostatin gene expression by acting as a strong enhancer even in the absence of cAMP stimulation. Site-directed mutagenesis followed by transient transfection assays indicated that SMSTAAT1, SMS-TAAT2, and SMS-UE, three previously identified homeodomain protein-binding regulatory elements that enhance transcription in pancreatic cells, act as repressors of transcription in neural cells. Electrophoretic mobility shifts assays indicate that those elements bind protein complexes that differ between neural and pancreatic cells. Our results support the notion that expression of the somatostatin gene in neural cells oc- curs via transcriptional mechanisms that are different from those regulating expression of the same gene in pancreatic cells. (Molecular Endocrinology 12: 1280-1293, 1998)

\section{INTRODUCTION}

Cells that synthesize polypeptide hormones acquire their specific phenotypes during embryonic development via molecular mechanisms that involve gene activation and repression. Upon terminal differentiation, different neuroendocrine cells express an ensemble of transcriptional activator and repressor proteins that interact on the promoter of target genes encoding specific neuropeptide hormone precursors. These interactions between a complex mixture of nuclear proteins and their target DNA sequences, which appear to follow a strict cell-specific combinatorial code tailored to distinct cellular phenotypes, modulate appropriate levels of cell-specific expression of each neuropeptide-encoding gene in basal conditions and in response to changes in the extracellular environment.

A particular neuropeptide-encoding gene may be expressed throughout the organism in a variety of tissues and cell types with different embryonic origins (1). Many of them are expressed in the central nervous system as well as in peripheral tissues, including the gastrointestinal tract and specific endocrine organs. However, whether cell-specific expression of a neuropeptide gene in ontogenically different tissues is regulated by similar or identical mechanisms remains unclear.

Somatostatin is a neuropeptide hormone whose expression is restricted to cells in the peripheral and central nervous systems, as well as to parafollicular 
cells of the thyroid gland, D cells of the digestive tract, and $D$ cells of the pancreatic islets of Langerhans (2). Among these tissues, the endocrine pancreas has provided an informative model with which to study transcriptional mechanisms of control of cell-specific somatostatin gene expression, due, in no small part, to the availability of a number of pancreatic cell lines that recapitulate phenotypic features of pancreatic islet cells. Using such cell lines, previous studies by several investigators have shown that pancreatic D cellspecific expression of the somatostatin gene is the consequence of the binding of a number of nuclear proteins to well defined DNA cis-regulatory elements located in its promoter region. These elements include a cAMP-response element (CRE) located in relative proximity to the TATA box (3-6), several tissuespecific enhancers that provide binding sites for homeodomain transcription factors (7-9), and several silencer elements (10).

In the central nervous system, somatostatin was first discovered in the hypothalamus and was found subsequently to be widely distributed in other areas, including hippocampus, cerebral cortex, and basal forebrain, where it appears to serve as an inhibitory neurotransmitter released from small interneurons (11). In the rat, the first somatostatin-positive cells in the forebrain appear at embryonic day 14 (E14) (12, 13). In some cells, this expression is transient, whereas in others it is maintained in the adult brain, and thus it has been proposed that in addition to its role as a neurotransmitter, somatostatin may have trophic effects on target cells during brain development (14-16).

The transcriptional mechanisms that control cellspecific somatostatin gene expression in the central nervous system are unknown. In the present study, we report on the establishment of conditionally immortalized somatostatin producing cell lines derived from rat embryonic brain. By using transient transfection assays, DNA mutagenesis, and DNA-protein binding assays, we show that expression of the somatostatin gene in neural cells is regulated by the strong positive activity of the CRE, which is under the influence of at least three negative acting upstream elements. A functional analysis of the somatostatin gene promoter in neural cells indicated that these negative-acting elements correspond to previously described pancreatic enhancers that bind homeodomain transcription factors.

\section{RESULTS}

\section{Establishment of Somatostatin-Producing Forebrain-Derived Immortalized Cells}

Two regions of the forebrain, the cerebral cortex and the hippocampus, were chosen as a source of cells for immortalization because somatostatin is expressed in cells in these regions during development and in the adult brain. Cells growing as primary cultures from embryonic cerebral cortex and hippocampus were infected with a recombinant retrovirus carrying genes encoding tsA58/U19 $(17,18)$, a temperature-sensitive mutant of the Simian Virus 40 large-T antigen (SV40T), and aminoglycoside phosphotransferase to confer resistance of the neomycin homolog G418. A total of 15 clonal cell lines were derived from G418-resistant colonies from hippocampal cultures, and 38 clonal cell lines were derived from cultured cerebrocortical cells. A subset of these cell lines was screened for expression of the somatostatin gene by RT-PCR. One cell line derived from embryonic hippocampus (RH1.C4 cells) and one derived from embryonic cerebral cortex (RC2.E10) exhibited levels of somatostatin transcripts comparable to those observed in control pancreatic islet D-like RIN-1027-B2 cells (Fig. 1A). At least three other cortical cell lines were found to express somatostatin, albeit at relatively lower levels (Fig. 1A).

Hippocampal RH1.C4 and cerebrocortical RC2.E10 cells were expanded and have been propagated continuously for more than $2 \mathrm{yr}$ (>70 passages) with no apparent change in phenotype. Both cell types proliferate in a serum-dependent manner and exhibit features of neural precursors that can differentiate under specific culture conditions, details of which have been previously reported (19) and will be published elsewhere. Somatostatin expression in these two cell types was confirmed by immunocytochemistry (Fig. 2). Somatostatin content of RH1.C4 and RC2.E10 cells, as determined by RIA (three determinations for each cell type in duplicate), was $340 \pm 20 \mathrm{fmol} / \mathrm{mg}$ and $260 \pm 60 \mathrm{fmol} / \mathrm{mg}$, respectively.

Since we used a temperature-sensitive mutant $\operatorname{SV} 40 T(17,18)$, we were able to determine whether the presence of SV40T affects somatostatin gene expression. For this purpose, RC2.E10 cells were incubated at the nonpermissive temperature (39 C) for $24 \mathrm{~h}$, and degradation of SV40T was confirmed both by Western immunoblotting (Fig. 1B) and immunocytochemically (not shown). Levels of somatostatin message in cells incubated at $39 \mathrm{C}$ were similar to those in cells incubated at the permissive temperature (33 C), indicating that the presence of SV40T does not significantly affect somatostatin gene expression (Fig. 1C).

\section{Positive- and Negative-Acting Promoter Elements Regulate Neural Cell Expression of the Somatostatin Gene}

To obtain information about the activity of the somatostatin gene promoter region in neural cells, we carried out transient transfection assays in hippocampal $\mathrm{RH} 1 . \mathrm{C} 4$ cells and in cortical RC2.E10 cells. Initially, we used the plasmid SMS900, a chloramphenicol acetyltransferase (CAT) reporter plasmid that contains a fragment of the somatostatin gene spanning nucleotides -900 to $+54(4,5)$, and compared its activity to that of a Rous sarcoma virus enhancer-driven CAT reporter (RSVCAT). Figure 3B shows that the level of expression of SMS900 CAT in RH1.C4 cells was sim- 
A
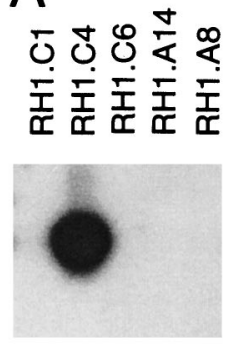

Hippocampal
응뚜 ผิ่ ปึ่

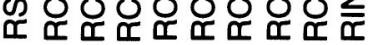

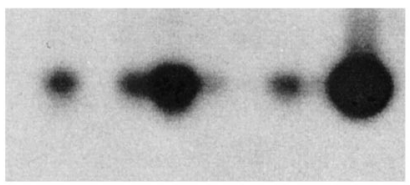

Cerebrocortical

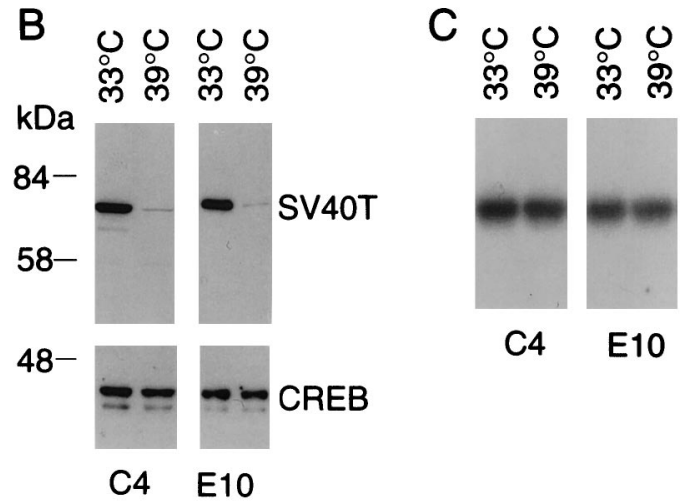

Fig. 1. Somatostatin Gene Expression in Cells Derived from Rat Embryonic Hippocampus and Cerebral Cortex

A, Somatostatin message detected by reverse transcriptase-PCR/Southern blot hybridization was found expressed in one (RH1.C4) of five hippocampal cell lines tested (left panel) and in several cerebrocortical cell lines (right panel). Of these, the highest levels, as compared with those of pancreatic islet RIN-1027-B2 cells (RIN-B2, right-most lane), were observed in RC2.E10 cells. B, Western immunoblot showing temperature-dependent degradation of SV40T (top panel) in hippocampal RH1.C4 cells (C4) and in cerebrocortical $\mathrm{RC} 2 . \mathrm{E} 10$ cells (E10). As a control, a shift to the nonpermissive temperature did not affect immunoreactive levels of CREB (bottom panel). C, Somatostatin message detected by reverse transcriptase-PCR/Southern blot hybridization in RH1.C4 (C4) and RC2.E10 (E10) cells incubated at either 33 C or $39 \mathrm{C}$.

ilar to that determined in pancreatic RIN-1027-B2 cells (5), whereas SMS900 CAT expression in RC2.E10 cells was lower.

To determine the approximate boundaries of transcriptional control regions of the somatostatin gene promoter that contain positive or negative DNA cisregulatory elements, we transfected somatostatin CAT reporter plasmids generated by sequential $5^{\prime}$-deletions of the fragment in SMS900 $(4,5)$. We found that a deletion to nucleotide -750 results in a significant decrease in CAT activity in both RH1.C4 and RC2.E10 cells (Fig. $3 \mathrm{C}$ ), suggesting the presence of enhancer elements upstream of that position. A more extensive deletion to nucleotide -550 resulted in values of CAT activity that were not significantly different from those obtained with SMS900, thus suggesting the presence of negative regulatory elements located between nucleotides -750 and -550 . The activity of the plasmids with deletions to nucleotides -425 and -345 was significantly lower than that of SMS900, although in RC2.E10 cells the level of expression of SMS425 was relatively higher than in $\mathrm{RH} 1 . \mathrm{C} 4$ cells (Fig. $3 \mathrm{C}$ ). Nonetheless, the decreased CAT activities exhibited by both plasmids indicated the removal of positive regulatory elements located between nucleotides -550 and -345 . A further deletion to nucleotide -250 restored CAT activity to levels not significantly different from those of SMS900 in RH1.C4 cells, but in RC2.E10 cells this deletion resulted in a significant increase in CAT activity ( $>2$-fold relative to SMS900), indicating the existence of repressor elements between nucleotides -345 and -250 . Additional deletions resulted in higher levels of expression in both cell types, but the observed increases in CAT activities were higher in RC2.E10 than in RH1.C4 cells. Thus, relative to SMS900, the levels of expression of SMS120, which contains a previously identified somatostatin upstream element (SMS-UE) and a CRE (5), were approximately 2- to 3-fold and 8-fold higher in $\mathrm{RH} 1$.C4 and RC2.E10 cells, respectively. Finally, removal of the SMS-UE by a deletion to nucleotide -65 , leaving intact the CRE, resulted in a further 5-fold and 15-fold increase in CAT activity in RH1.C4 and RC2.E10 cells, respectively. This increase in CAT activity was dependent on the presence of the CRE, as indicated by the observation that its removal by a deletion to nucleotide -42 , retaining a minimal promoter that contains the TATA box, resulted in low levels of CAT activity (Fig. 3C).

\section{Requirement of the CRE for Promoter Activity in RC2.E10 Cells}

The above experiments suggest that the CRE plays a prominent role as a DNA cis-regulatory element mediating somatostatin gene expression in neural cells. Indeed, it appears that somatostatin gene transcription is potently activated by this element, and that its activity is down-regulated by upstream negative modulatory elements. To examine this notion in detail, we chose to focus our attention on cortex-derived RC2.E10 cells, because the CAT activity generated by SMS65 in these cells was significantly higher than in hippocampus-derived $\mathrm{RH} 1 . \mathrm{C} 4$ cells, indicating that the CRE is more potent in the former than in the latter cell type. In addition, our 5'-deletion analysis suggested that in RC2.E10 cells relatively potent repressor elements may be needed to counteract the activity generated by the CRE.

We introduced an internal four-base deletion in SMS900 that disrupts the CRE motif (from TGACGTCA to TG-CA), and determined the CAT activity generated by the resulting plasmid, SMS900 $\triangle \mathrm{CRE}$, after transient transfection into RC2.E10 cells. These experiments indicated that the integrity of the CRE is required for somatostatin promoter function in neural cells, because dis- 


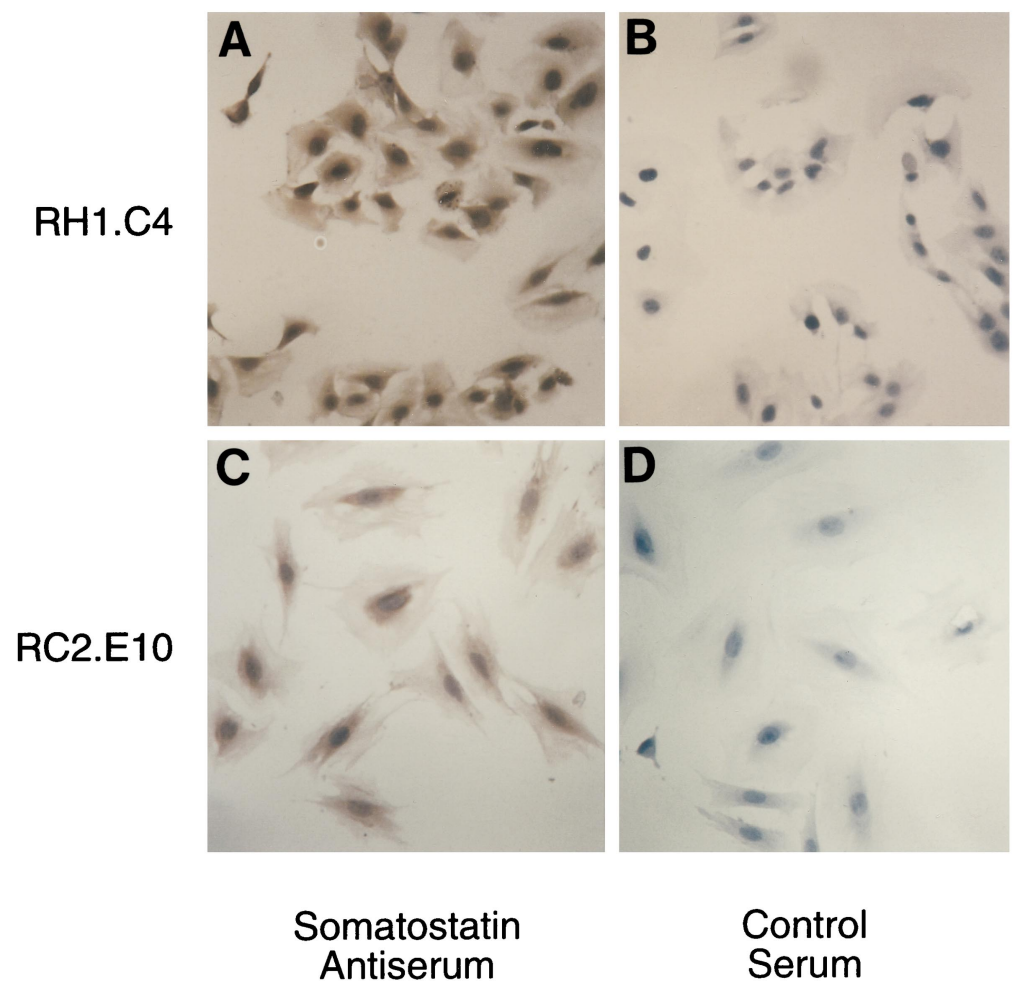

Fig. 2. Immunocytochemistry of Somatostatin in Hippocampus-derived RH1.C4 Cells (A and B) or Cerebrocortex-Derived RC2.E10 Cells (C and D)

Control cells were incubated with normal rabbit serum in place of the somatostatin-specific antiserum (1:500). Nuclei were stained with hematoxylin.

ruption of the CRE resulted in reduced CAT activities indistinguishable from background levels (Fig. 3A). In addition, these results lend additional support to the hypothesis that the resulting transcriptional activity imparted by the full-length promoter is the result of the activity of repressor elements that counteract the transcriptional effect of positive regulatory elements that require the presence of an intact CRE.

\section{DNA Elements Containing "TAAT" Motifs in the Somatostatin Promoter Act as Negative Modulators of Transcription in Neural Cells}

To search for additional promoter elements located upstream from the CRE that regulate somatostatin gene expression in neural cells, we studied promoter elements that have been shown previously to regulate somatostatin gene expression via binding of homeodomain transcription factors in pancreatic cells.

The SMS-UE (nucleotides -114 to -78 ) contains a so-called domain B (UE-B) with a core TAAT motif that binds homeodomain transcription factors in pancreatic cells $(5,7,8,20)$. Two other homeodomainbinding regulatory elements in the somatostatin gene promoter, SMS-TAAT1 and SMS-TAAT2, located at positions -449 to -445 and -295 to -292 , respectively, have been described $(8,20)$. Inspection of the DNA sequence of the somatostatin promoter revealed the existence of a previously unidentified TAAT motif located between nucleotides -368 and -365 , which we named SMS-TAAT3. To determine whether these elements regulate the expression of the somatostatin gene in neural cells, we carried out transient transfections in RC2.E10 cells and tested CAT activities of plasmids in which the TAAT motif of each one of them had been altered by site-directed mutagenesis. Reduced binding of nuclear proteins from RC2.E10 cells to these mutated sequences was confirmed by electrophoretic mobility shift assay (EMSA) (data not shown).

Disruption of each one of the aforementioned TAAT motifs independently resulted in increases in CAT activity relative to the wild-type SMS900 (Fig. $4 A)$. The highest increase ( $\sim 4$-fold) was found with plasmid SMS900T1M (SMS-TAAT1 mutant), followed by both SMS900T2M (SMS-TAAT2 mutant) and SMS900UEBM (SMS-UE-B mutant). Disruption of SMS-TAAT3 (plasmid SMS900T3M) only resulted in a modest $(<2$-fold) increase in CAT activity. Mutations of more than one of these motifs simultaneously, in different combinations, did not result in further increases in CAT activity (data not shown).

These experiments suggest that SMS-TAAT1, SMSTAAT2, and SMS-UE-B (and to a lesser extent SMSTAAT3) negatively regulate transcription of the soma- 
A

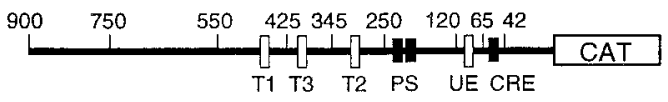

B

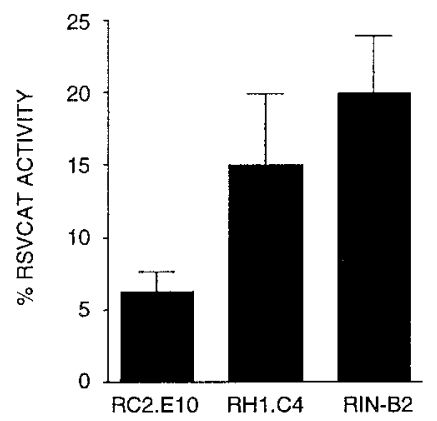

C

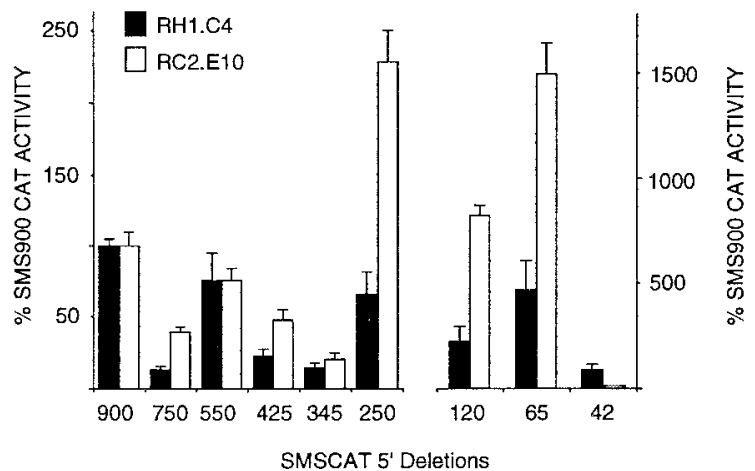

Fig. 3. Somatostatin Promoter Activity in Neural Cells Derived from Embryonic Rat Forebrain

A, Schematic depiction of the rat somatostatin/CAT fusion gene SMS900. Numbers on top represent nucleotide positions relative to the transcriptional start site, used to generate $5^{\prime}$-deletion constructs. The relative positions of the regulatory elements SMS-TAAT1 (T1), SMS-TAAT2 (T2), SMS-TAAT3 (T3), proximal silencers 1 and 2 (PS, Ref. 10), SMS-UE (UE), and CRE are indicated. B, Relative activity of the SMS900 CAT reporter gene transiently transfected in somatostatinproducing cell lines derived from rat embryonic cerebral cortex (RC2.E10), rat embryonic hippocampus (RH1.C4), or rat pancreatic islet RIN-1027-B2 (RIN-B2). Values are expressed as percentages of the activities elicited by the Rous sarcoma virus/CAT fusion gene transfected in the same experiments. C, Relative CAT activities obtained after transient transfections of somatostatin-CAT 5'-deletion plasmids in RH1.C4 or RC2.E10 cells. Values are expressed as percentages of the activities elicited by SMS900 CAT transfected in the same experiments. Note the different scale on the right panel to show higher values of CAT activity obtained with plasmids deleted to positions -120 and -65 .

tostatin promoter in neural cells, an effect opposite to that previously described in pancreatic cells $(5,7,8$, 20). However, mutation of each one of them alone or in combination did not result in levels of CAT activity as high as those generated by SMS65, which contains the CRE as the only active cis-acting element (see Fig. $3 \mathrm{C}$ for comparison) suggesting that either they are weak repressors, or that additional non-TAAT-containing negative modulatory elements exist at different locations on the somatostatin promoter. To gain insight into which one of these possibilities is more likely to be correct, we tested the relative strength of each one of these elements in isolation in suppressing CREdriven transcription. To this end, we constructed plasmids by inserting synthetic oligonucleotides corresponding to SMS-TAAT1, SMS-TAAT2, or SMSTAAT3 immediately upstream from the CRE in the plasmid SMS65 and carried out transient transfections to compare the CAT activity generated by these plasmids with that generated by SMS65 in RC2.E10 cells. Initially, we determined that a 4-bp deletion in SMS65 that disrupts the CRE motif results in a significant reduction in CAT activity (Fig. 4B).

Placing either SMS-TAAT1 or SMS-TAAT2 immediately upstream from the CRE resulted in a marked decrease in SMS65 CAT activity (Fig. 4B). The decrease observed with TAAT1-SMS65 was more pronounced than that observed with TAAT2-SMS65, resulting in levels of CAT expression barely above background levels. In contrast, SMS-TAAT3 did not significantly reduce levels of SMS65 CAT expression. Thus, SMS-TAAT1 and SMS-TAAT2, but not SMSTAAT3, appear to be relatively strong repressors of CRE-dependent transcription. In an analogous manner, our $5^{\prime}$-deletion experiments indicated that SMS-UE-B can also repress CRE-mediated transcription (compare the activities of SMS120 and SMS65 in Fig. 3C).

\section{Binding of Nuclear Proteins to TAAT-Containing Elements}

The activities of SMS-TAAT1, SMS-TAAT2, and SMSUE-B as DNA cis-acting elements that control somatostatin gene expression have been previously studied in pancreatic cells, where they appear to act as positive regulatory elements. Because our studies indicate that those elements act as transcriptional repressors in neural cells, it was of interest to determine whether the complement of nuclear proteins that bind to them is different in neural and in pancreatic cells. For that purpose, we carried out EMSA with synthetic oligonucleotides corresponding to SMS-TAAT1, SMS-TAAT2, SMS-TAAT3, or SMS-UE-B, using nuclear extracts from cortical RC2.E10 cells or from pancreatic RIN1027-B2 cells. When the SMS-TAAT1 probe was used, three distinct DNA-protein complexes were found with nuclear extracts from RC2.E10 cells (Fig. 5). Specificity of these complexes was determined by competition with unlabeled SMS-TAAT1 oligonucleotide added in excess to the binding reaction. Addition of an oligonucleotide of unrelated sequence failed to compete. A similar pattern was found when SMSTAAT2 or SMS-TAAT3 probes were used, with the exception that an additional complex with relatively fast electrophoretic mobility (complex 4) was found with SMS-TAAT3 (Fig. 5). 

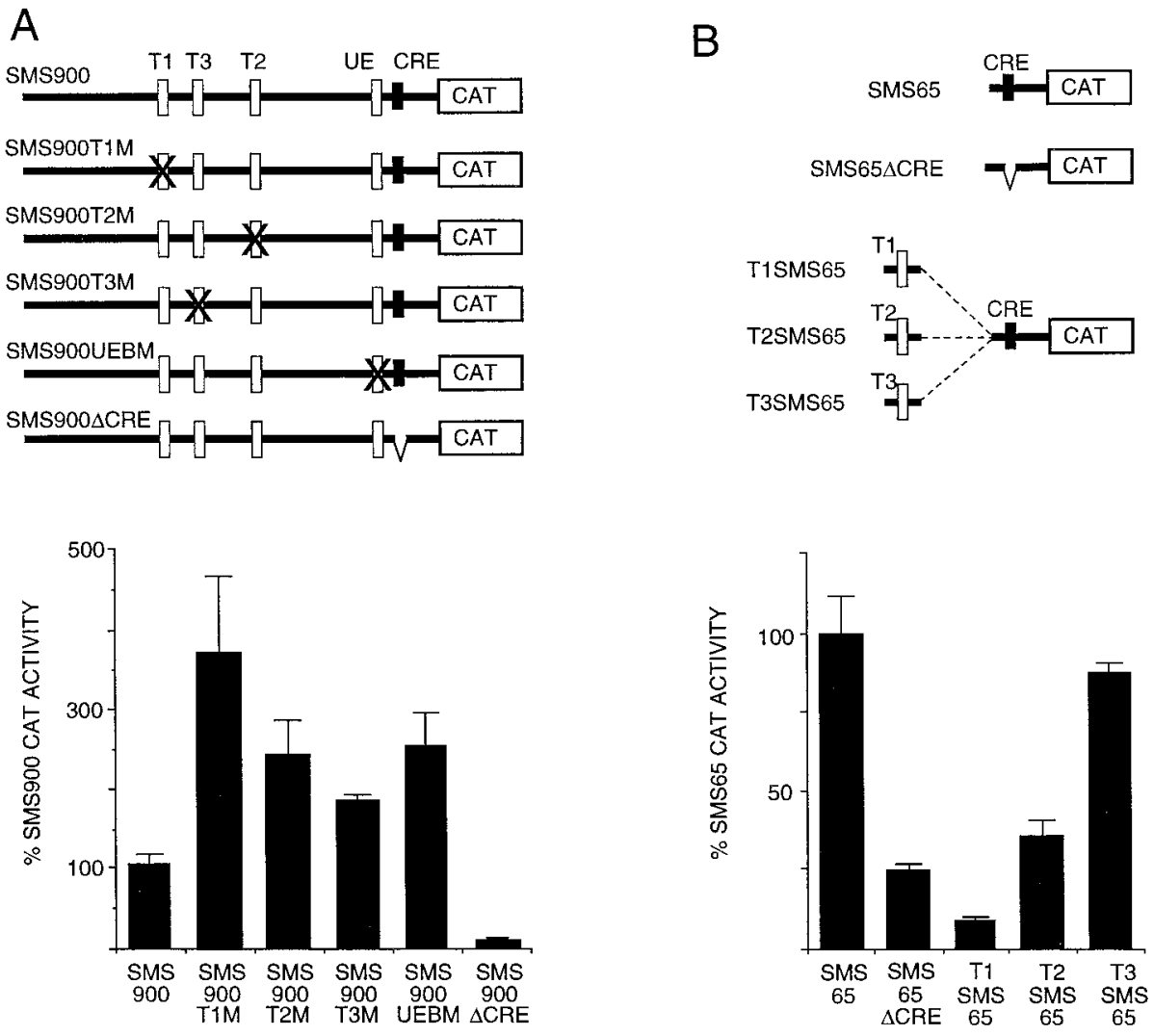

Fig. 4. Repressor Activity of TAAT-Containing Elements of the Somatostatin Promoter in RC2.E10 Cells

A, Top panel, schematic representation of wild-type (SMS900) and mutated somatostatin CAT reporter constructs used to transfect embryonic cerebral cortex-derived RC2.E10 cells. TAAT-containing elements are depicted as open boxes, and their mutated versions are indicated as crossed-out boxes. The elements are: T1, SMS-TAAT1; T2, SMS-TAAT2; T3, SMS-TAAT3; and UE, SMS-UE-B. Bottom panel, relative CAT activities of the above plasmids observed after transfections in RC2.E10 cells. Values are expressed as percentages of the activities elicited by wild-type SMS900 CAT. B, Effects of SMS-TAAT1 (T1), SMS-TAAT2 (T2), or SMS-TAAT3 (T3) on basal CRE-dependent transcription. SMS65 contains a TATA box and a CRE, which is deleted in SMS65 $\triangle$ CRE (5). Values are expressed as percentages of the CAT activities elicited by SMS65.

When nuclear extracts from pancreatic RIN1027-B2 cells were used, clear differences in the pattern of retarded bands generated with each probe were observed (Fig. 5). Binding of nuclear proteins to the SMS-TAAT1 probe resulted in the generation of two relatively strong complexes of similar intensities that appear to migrate at the levels of complexes 1 and 3 , respectively, detected with nuclear extracts of RC2.E10 cells. Complex 3 generated with nuclear extracts of RIN-1027-B2 cells was found to consist of two distinct bands that migrate electrophoretically in close proximity. Another difference detected was that the intensity of complex 2 from pancreatic cell nuclear extracts was consistently weaker than its counterpart from neural cell nuclear extracts. In addition, a doublet of relatively low intensity and slow electrophoretic mobility (Fig. 5, arrow) was detected with RIN-1027-B2 nuclear extracts but not with RC2.E10 nuclear extracts. Similar differences were found when SMSTAAT2 and SMS-TAAT3 were used, with the exception that when the SMS-TAAT3 probe was used with nuclear extracts of RIN-1027-B2 cells, no complex was found migrating slower than complex 1. SMS-TAAT3specific complex 4 was found in both neural and pancreatic cell nuclear extracts (Fig. 5).

When the UE-B probe was used, three closely migrating bands with relatively slow electrophoretic mobilities were detected with nuclear extracts of RC2.E10 cells, with the fastest one exhibiting the strongest intensity (Fig. 5). In contrast, only two complexes were detected when RIN-1027-B2 nuclear extracts were used, and in this case the strongest intensity was exhibited by the band with slower electrophoretic mobility.

To investigate the presence of proteins that recognize somatostatin TAAT sites in the developing rat brain, we prepared nuclear extracts from the forebrain of E17 fetuses removed from timed-pregnant rats and assessed DNA-protein binding by EMSA. We found that the pattern of bands generated by SMS-TAAT1 and SMS-TAAT2, and SMS-UE-B in extracts of E17 forebrains shows similarities with those found with nuclear extracts of RC2.E10 cells. For SMS-TAAT1 and SMS-TAAT2, we detected complexes 1, 2, and 3, 

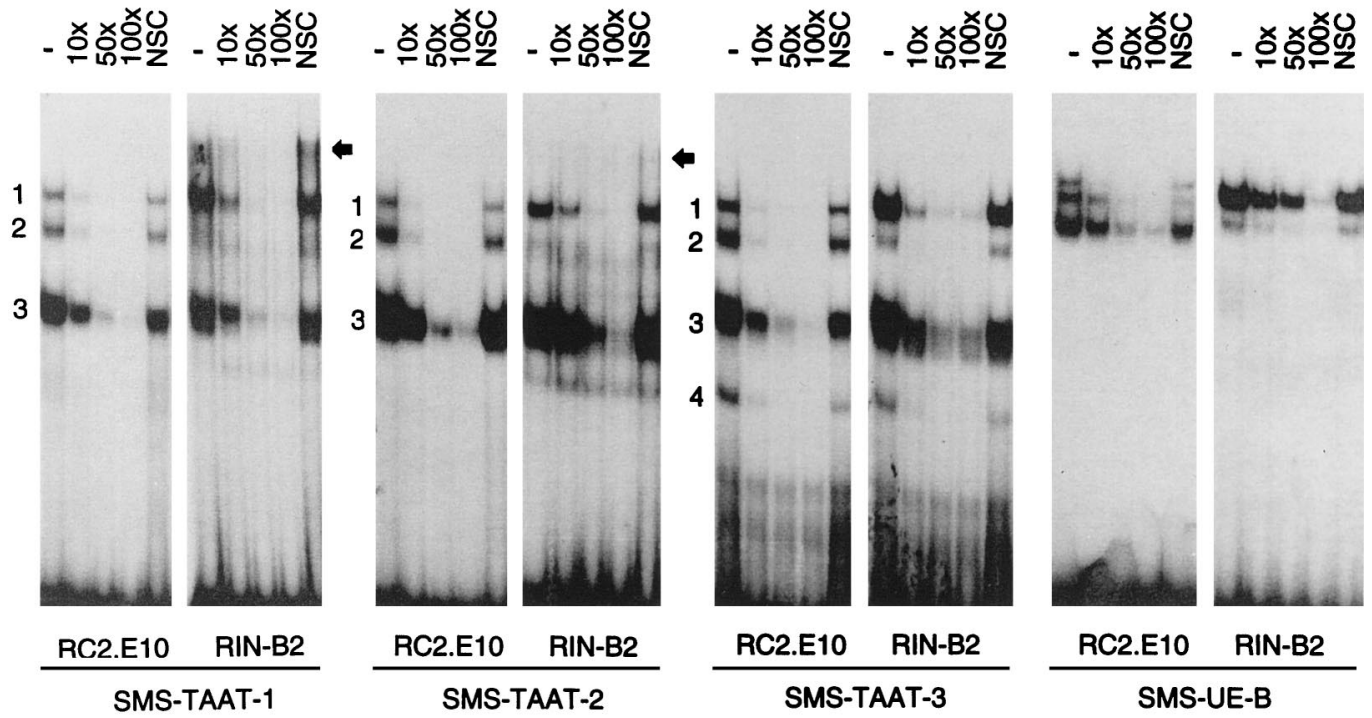

Fig. 5. EMSA with Nuclear Extracts of Somatostatin-Producing Cells Derived from Embryonic Cerebral Cortex (RC2.E10) or Pancreatic Islets (RIN-B2)

Oligonucleotide probes used in each assay are indicated at the bottom. Nuclear extracts were incubated in the absence (-) or presence of competing oligonucleotides [10-, 50- or 100 -fold molar excess $(10 \times, 50 \times$, or $100 \times$, respectively)] of identical probe sequence, or in the presence of a nonspecific competing (NSC) oligonucleotide of unrelated sequence used in a 100-fold molar excess. Complexes numbered 1-4 are described and discussed in the text. Arrows indicate protein-DNA complexes of slow electrophoretic mobility observed in pancreatic, but not in neural, extracts.

which were found to comigrate with the corresponding ones observed with nuclear extracts of RC2.E10 cells (Fig. 6A). As shown in Fig. 6A, specificity of binding of these complexes to DNA was confirmed by competition with unlabeled oligonucleotides. When we used the SMS-UE-B probe, three closely migrating complexes were found in embryonic forebrain extracts, with similar electrophoretic mobilities to those observed with RC2.E10 nuclear extracts (Fig. 6B). Specificity of complexes from embryonic forebrain bound to SMS-UE-B was confirmed by competition experiments with nonlabeled oligonucleotides (not shown). Thus, these experiments support the notion that in the developing brain in vivo, somatostatin gene-regulatory elements are recognized by similar proteins to those found in cortex-derived RC2.E10 cells.

We also investigated whether SMS-TAAT1, SMSTAAT2, and SMS-UE-B bind homeodomain transcription factors in neural cells, as has been described to be the case in pancreatic cells $(8,9,20)$. For that purpose, we carried out EMSA in the presence of an antiserum $(\mathrm{Hm}-66)$ raised against IDX-1 (8), an antennapedia-like homeoprotein expressed in pancreas and duodenum that regulates somatostatin gene transcription in pancreatic cells by binding to those elements $(8,9,20)$. This antiserum recognizes the homeodomains of related transcription factors (J. Habener, personal communication), and therefore any perturbation in the banding pattern observed in its presence would be indicative of the binding of homeodomain-type transcription factors to the corresponding oligonucleotides. Figure $6 \mathrm{~B}$ shows that the presence of this anti- serum in the binding reaction resulted in the disappearance of the upper band detected with the SMS-UE-B probe, using either RC2.E10 or E17 forebrain nuclear extracts. Addition of the antiserum to the binding reaction did not result in any modification of the band pattern observed with SMS-TAAT1 or SMSTAAT2. Thus, these experiments suggest that SMSUE-B binds a homeodomain-type protein present in neural cells.

\section{Stimulation of Somatostatin Gene Transcription by cAMP}

Previous studies carried out in pancreatic cells have provided evidence in support of synergistic interactions between CRE-binding proteins and proteins that bind to SMS-UE or TAAT elements $(5,21)$. However, those studies were carried out in pancreatic cell lines in which somatostatin gene transcription is not stimulated by CAMP, likely due to a defect in the phosphorylation of nuclear factor CRE-binding protein (CREB) (6). Therefore, we investigated whether regulatory TAAT elements participate in the modulation of the transcriptional responses induced by CAMP in neural cells. To this end, we transfected RC2.E10 cells with either SMS900 or with similar plasmids, in which each one of the TAAT elements had been individually mutated, and treated them with the CAMP analog 8-Br-CAMP (1 mM). Treatment of RC2.E10 cells with 8-Br-cAMP for $16 \mathrm{~h}$ resulted in an 8-fold increase in the CAT activity generated by SMS900 (Fig. 7). That response was abolished by deletion of four bases in 
A

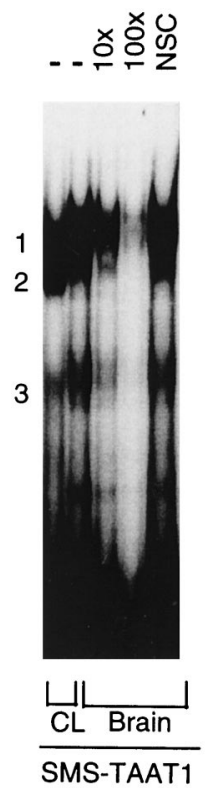

B

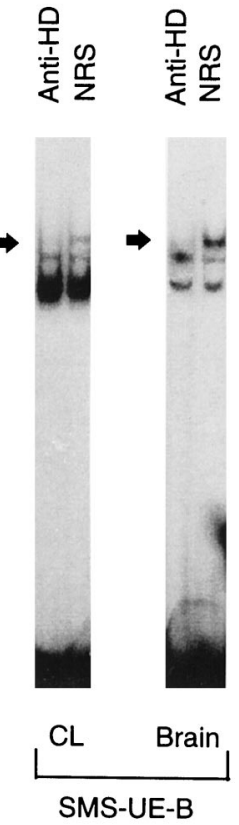

Fig. 6. Somatostatin TAAT-Containing Elements Bind Nuclear Proteins from Developing Rat Forebrain

A, EMSA with nuclear extracts of embryonic day 17 rat forebrain (Brain) showing protein complexes bound to SMSTAAT1 or SMS-TAAT2 oligonucleotide probes. For comparison, extracts prepared from RC2.E10 cells (CL) were also assayed. Nuclear extracts were incubated in the absence (-) or presence of competing oligonucleotides [10- or 100-fold molar excess $(10 \times$ or $100 \times$, respectively)] of identical sequence to each probe, or in the presence of a nonspecific competing (NSC) oligonucleotide of unrelated sequence used in a 100-fold molar excess. Complexes numbered 1-3 are described and discussed in the text. B, EMSA showing binding of nuclear proteins prepared from RC2.E10 cells (CL) or from embryonic day 17 rat forebrain (Brain) to an oligonucleotide probe corresponding to the somatostatin SMSUE-B. Binding reactions were carried out in the presence of an antiserum that recognizes homeodomain-type proteins (Anti-HD, Ref. 8) or normal rabbit serum (NRS). Arrows indicate the absence of the top protein-DNA complex in the presence of the specific antiserum.

the CRE (Fig. 7). The magnitude of the response of SMS900 to 8-Br-cAMP stimulation was blunted by mutations in SMS-TAAT1 (4.9-fold), SMS-TAAT2 (3.4fold), or SMS-UE-B (5.1-fold) but not significantly altered by mutations in SMS-TAAT3 (7.7-fold).

One possible interpretation of these results is that mutations of SMS-TAAT1, SMS-TAAT2, or SMS-UE-B relieve repression of basal transcription and thus the fold-stimulation to cAMP may be secondarily reduced. Alternatively, it is possible that independently of their role as negative regulators of basal transcription, some TAAT elements may facilitate CRE-dependent cAMP-induced transcription of the somatostatin gene in cerebrocortex-derived cells. To further explore this possibility, we carried out transient transfections in RC2.E10 cells to evaluate whether the presence of

TAAT elements immediately upstream from the CRE alters the response of SMS65 to CAMP stimulation.

Treatment of RC2.E10 cells with 8-Br-cAMP resulted in a 2.8-fold increase in the CAT activity generated by SMS65 (Fig. 7). Placing either TAAT3 or SMS-UE-B upstream from the CRE did not significantly alter the strength of the response to 8-Br-cAMP (2.3-fold and 2.7-fold, respectively) (Fig. 7). However, the presence of SMS-TAAT2 resulted in a significant increase in the fold stimulation elicited by $8-\mathrm{Br}$-cAMP (4.6-fold, $P<0.05$, Student's $t$ test, as compared with SMS65). In contrast, SMS-TAAT1 inhibited CAMPdependent stimulation of SMS65 (Fig. 7). Thus, these results are consistent with the notion that, whereas TAAT1 represses both basal and CAMP-stimulated transcription, TAAT2 represses basal transcription but appears to facilitate cAMP-stimulated transcription.

\section{DISCUSSION}

To date, studies to identify and characterize DNA cisregulatory elements that participate in the control of somatostatin gene expression have been carried out in nonneural cells, using primarily pancreatic islet cell lines derived from endocrine tumors $(4-10,21)$. In the present study, we found evidence that in neural cells, as in pancreatic cells, the expression of the somatostatin gene appears to be regulated by the balanced activity of both negative- and positive-acting regulatory elements distributed throughout the promoter region. However, the location and/or function of regulatory elements differ between pancreatic and neural cells.

A progressive elevation in somatostatin CAT activity was observed, especially in cortical RC2.E10 cells, when the size of the promoter truncations generated by 5 '-deletions increased, yielding levels of expression significantly higher than those observed with the fulllength promoter. This was particularly evident as the proximity of the $5^{\prime}$-end of the remaining promoter fragment approached position -65 , immediately upstream of the CRE. Thus, it appears that the stepwise removal of upstream negative modulatory elements results in the increasing manifestation of the activity of a strong positive regulatory element that would otherwise remain relatively repressed to maintain appropriate levels of expression. Our data identified the CRE as the predicted strong positive regulator, not only because of its location downstream to nucleotide -65 , but also because its removal by a $5^{\prime}$-deletion to position -42 or by an internal 4-base deletion in the fulllength promoter results in levels of CAT activity indistinguishable from background. Thus, the CRE appears to play a pivotal role in the regulation of basal somatostatin gene expression in neural cells. Studies in pancreatic and thyroid cells indicate that the somatostatin CRE recognizes a complex array of transcription factors generating between three and seven com- 


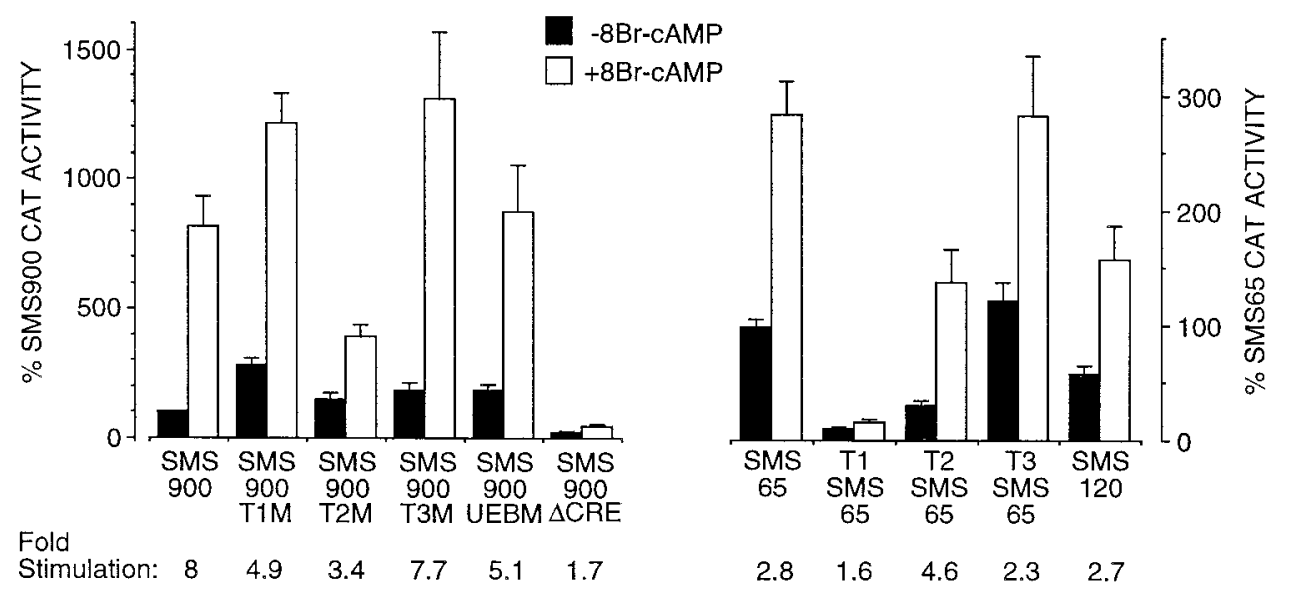

Fig. 7. Effects of cAMP Stimulation on the Expression of Somatostatin CAT Reporter Plasmids after Transfections in RC2.E10 Cells

Plasmids used for transfections are identical to those depicted in Fig. 4, with the exception of SMS120, which is described in Fig. 3. Transfected cells were treated with 8-Br-cAMP $(1 \mathrm{mM})$ for $16 \mathrm{~h}$ before harvesting. Values are expressed as percentages of the CAT activity elicited by SMS900 (left) or SMS65 (right) in basal conditions.

plexes by EMSA $(4,10,22)$. We have observed a similar degree of complexity using nuclear extracts of RC2.E10 cells (our unpublished results), although the identity of the proteins that mediate basal CRE-dependent transcription in neural cells remains to be determined.

No evidence of regulatory elements has previously been reported in studies with pancreatic cells in a distal region of the promoter spanning nucleotides -750 to -900 . We observed that the decrease in CAT activity after the deletion of this region was more pronounced in hippocampal RH1.C4 cells $(13 \%$ of SMS900) than in cortical RC2.E10 cells $(40 \%$ of SMS900). Somatostatin message levels appeared higher in RH1.C4 than in RC2.E10 cells, and our studies comparing the activity of SMS900 to that of RSVCAT suggest that the somatostatin gene is more efficiently expressed in RH1.C4 than in RC2.E10 cells. Therefore, these results suggest the existence of positive elements between -900 and -750 that act more efficiently in hippocampal than in cerebrocortical cells and thus may play a role in the control of regionspecific expression within the central nervous system.

The presence of a neuron-restricted silencer element (NRSE) (23-29) in the promoters of certain neural and pancreatic genes suggests a possible mechanism for their expression both in neurons and in pancreatic islet cells (30-32). Although the somatostatin gene promoter does not contain an NRSE-like sequence, our studies indicated the presence of several regions of the somatostatin promoter that contain transcriptional repressor elements. In hippocampal RH1.C4 cells, $5^{\prime}$-deletion experiments allowed us to map the location of these repressor elements within positions -750 to $-550,-345$ to -250 , and -120 to -65 . In pancreatic cells, distal negative control elements have only been documented between nucleotides -425 and -345 , but not upstream from that position (5).
Therefore, repressor elements located between nucleotides -750 and -550 may represent neural-specific elements important for the modulation of adequate levels of expression of the somatostatin gene in the nervous system.

Notably, deletion of a region containing PS1 and PS2, two previously identified proximal silencer elements that repress transcription in pancreatic cells, located between nucleotides -250 and -120 (10), did not result in an increase of activity in hippocampal cells, suggesting that these elements are not active in these cells or that this region contains additional unidentified positive elements that offset the activity of PS1 and PS2. However, in cerebrocortical RC2.E10 cells, PS1 and PS2 are likely to be active, because a deletion from nucleotides -250 to -120 resulted in a significant increase in CAT activity. Thus, it appears that the region spanning nucleotides -345 to -65 contains transcriptional repressor elements, including SMS-TAAT2 (between -345 and -250 ), PS1 and PS2 (between -250 and -120 ), and SMS-UE-B (between -120 and -65$)$, which seem to be required for downregulation of the strong transcriptional activity elicited by the CRE in RC2.E10 cells.

SMS-TAAT1 was found to act as a strong repressor of CRE-dependent transcription in RC2.E10 cells. However, our initial 5'-deletion experiments did not allow us to predict that SMS-TAAT1 would act as a repressor, because removal of the fragment spanning -550 to -425 (SMS-TAAT1 is located between -449 and -445 ) resulted in decreased rather than increased transcriptional activity. This apparent discrepancy could be explained by the existence of two positive regulatory elements in close proximity to SMS-TAAT1 that can provide binding sites for GATA-type transcription factors (33).

The negative regulatory elements characterized in this study, SMS-TAAT1, SMS-TAAT2, and SMS-UE-B, 
have been previously identified in pancreatic cells as enhancers that bind homeodomain-type transcription factors $(8,9,20,21)$, and it is likely that in neural cells these elements also bind homeodomain proteins. A number of homeodomain-encoding genes, including Isl-1, Pax-6, Pbx, and Brn-4, have been found to be expressed in both endocrine pancreas, where some of them regulate somatostatin gene transcription, and brain $(20,21,34-38)$. Our EMSA data suggest that a protein with a homeodomain that resembles that of IDX-1 protein is present in neural cells and binds to SMS-UE-B. Although IDX-1 gene expression has been considered to be restricted to stomach, duodenum, and pancreas, it is possible that a gene encoding a protein similar to IDX-1 is expressed in the central nervous system (39). SMS-TAAT1 and SMS-TAAT2 do not appear to bind an IDX-1-like protein. However, a homeodomain protein related to Orthodenticle and Pax may bind to these elements (our unpublished observations).

It remains to be determined whether homeodomain transcription factors that recognize TAAT elements in neural cells act as transrepressor proteins or whether they act as transactivators that compete for binding to the same elements with nonhomeodomain-type repressor proteins. Although many homeodomain transcription factors function as transactivator proteins to stimulate transcription of target genes, it has been shown that a number of homeodomain proteins act as transcriptional repressors on the promoter of neural $(40-45)$ as well as nonneural genes (46-48). Evidence indicates that these proteins are composed of modular domains, some of which mediate activation whereas others mediate repression $(46,49-51)$. Thus, it appears that the overall transcriptional activity of a given homeodomain protein is the result of unique combinations of positive and negative acting regions operating according to determined molecular environments in different cell types.

It is possible that both positive- and negative-acting transcription factors bind to TAAT-containing elements of the somatostatin promoter so that the transcriptional activity imparted by these DNA-regulatory sequences is the result of the combined effects of both positive and negative trans-acting proteins. Thus, in pancreatic RIN-1027-B2 cells, binding of activator homeoproteins would predominate over repressor proteins, whereas the opposite would occur in neural RC2.E10 cells. Consistent with this model, our data generated by EMSA suggest that complex 2 on SMSTAAT1 and SMS-TAAT2, present in nuclear extracts of RC2.E10 cells but almost absent in those of RIN1027-B2 cells, may correspond to a repressor protein. Conversely, complex 1, more prominent in RIN1027-B2 cells than in RC2.E10 cells, may correspond to a transcriptional transactivator. Notably, SMSTAAT3 binds an additional complex (complex 4) not detected on SMS-TAAT1 or SMS-TAAT2. Since SMSTAAT3 did not show a significant negative activity, it is possible that complex 4 corresponds to a transcrip- tional transactivator complex whose influence would counteract the overall repressor activity of the other complexes apparently shared with SMS-TAAT1 and SMS-TAAT2. Nevertheless, it is also possible that complexes with similar electrophoretic mobilities in pancreatic and in neural cells correspond to related, but not identical, proteins with small differences in their amino acid sequences that could account for their activities as activators or repressors $(40,52,53)$, or even to identical proteins that may have bimodal properties, functioning as activators in some cell types and as repressors in others $(41,43,51,54)$. Efforts to elucidate the identities of the proteins that bind to somatostatin TAAT elements are underway in our laboratory.

That at least one of the TAAT-containing elements of the somatostatin gene promoter characterized in the present study is targeted by both positive and negative DNA-binding proteins is also supported by our data on CAMP-induced somatostatin gene transcription, which suggest that SMS-TAAT2 subserves a dual role as a negative modulator in basal conditions and as a positive facilitator of transcription under conditions of CAMP-dependent stimulation. Earlier studies have identified CREB, phosphorylated by protein kinase A in response to CAMP, as a major transactivator of somatostatin gene transcription in response to cAMP stimulation. However, the somatostatin CRE can also be recognized by other transcription factors such as CCAAT/enhancer-binding protein- $\beta$ (C/EBP $\beta)$ and C/ATF, which function as potent transactivators of somatostatin gene transcription in basal conditions via CREB-independent mechanisms (6). Thus, it is possible to hypothesize that positive-acting proteins bound to SMS-TAAT2 could facilitate phospho-CREB-dependent transcription via functional or physical interactions with phosphorylated CREB or with certain coactivators such as CREB-binding protein or TATA boxassociated factors. On the other hand, negative acting SMS-TAAT2-binding proteins would interact with a different set of CRE-binding or TATA box-associated proteins, as it has been shown that some amino acid sequences that act as repressor domains of homeodomain proteins can interact with specific components of the RNA polymerase II complex (55-57).

During development, somatostatin-expressing cells in the central nervous system appear first in the primordium of the E14 hypothalamus, and other telencephalic regions are recruited later $(12,13,15,16)$. As the central nervous system develops, somatostatin is expressed in differentiating neurons as well as in glial cells, but the number of somatostatin-positive cells fluctuates. Thus, in some areas the number of somatostatin-positive cells increases progressively and remains unchanged in the adult organism, whereas in other regions somatostatin gene expression is transient, increasing first and then decreasing until it disappears. This pattern of gene expression suggests a developmentally regulated dynamic interplay between positive- and negative-acting transcription factors, 
some of which may use TAAT-containing sites as cisacting targets. Identification of these neurally expressed transcription factors and elucidation of their complex interactions on the somatostatin promoter will shed light on our understanding of the molecular mechanisms that regulate the expression of a single gene in tissues of different embryological origins.

\section{MATERIALS AND METHODS}

\section{Materials}

DNA-modifying enzymes were purchased from New England Biolabs (Beverly, MA), Boehringer Mannheim Biochemicals (Indianapolis, IN), or Promega (Madison, WI). Radioactive compounds were obtained from DuPont-New England Nuclear (Boston, MA). Nucleotides were purchased from Pharmacia-LKB (Piscataway, NJ). Tissue culture media were prepared by the Cell Culture Core Facility of the Reproductive Endocrine Sciences Center at Massachusetts General Hospital, and reagents were obtained from GIBCO-BRL (Grand Island, NY). All other reagents were obtained from Sigma Chemical Co. (St. Louis, MO).

\section{Establishment of Immortalized Forebrain-Derived Cells}

Primary cultures of cells from developing cerebral cortex and hippocampus, two brain regions that contain somatostatinproducing neurons (12), were prepared from E16 fetuses removed from timed-pregnant Sprague Dawley rats. After careful removal of the meningeal membranes, the cerebral cortex was separated from the rest of the brain, and the developing hippocampi were dissected as described (58). Cells from these structures were dispersed, seeded onto polyornithine-coated plates, and infected $24 \mathrm{~h}$ later by a replication-defective recombinant retrovirus derived from the Moloney murine leukemia virus that contains a neomycinresistant gene and an SV40T oncogene encoding tsA58/U19, a temperature-sensitive mutant allele $(17,18)$. Retroviral particles (titer $10^{5} \mathrm{cfu} / \mathrm{ml}$ ) were produced by a $\Psi-2$ packaging fibroblast cell line (F4 subclone, kindly provided by Dr. G. Almazan, McGill University, Montreal, Quebec, Canada). Retrovirus-containing conditioned medium from $\Psi$-2 cells was applied directly onto primary cultured cells in the presence of $8 \mu \mathrm{g} / \mathrm{ml}$ polybrene (Sigma). Cells were incubated at $33 \mathrm{C}$ in DMEM supplemented with $10 \%$ FBS in the presence of the neomycin analog G418 (GIBCO Laboratories, Grand Island, NY). Resistant colonies appeared 3-5 weeks later and were individually picked using cloning rings and expanded. After five to six passages, a fraction of cells from each colony was frozen in liquid nitrogen.

Rat islet somatostatin-producing RIN-1027-B2 (59) cells were grown in DMEM supplemented with $10 \%$ FBS. All cell lines were cultured in the presence of penicillin $(100 \mathrm{U} / \mathrm{ml})$ and streptomycin $(10 \mu \mathrm{g} / \mathrm{ml})$.

\section{RT-PCR, Immunocytochemistry, and RIA}

Total RNA $(10 \mu \mathrm{g})$ purified by $\mathrm{CsCl}$ gradient centrifugation from individual cell lines was primed with poly-(dT) 15 and incubated with avian myeloblastosis virus (AMV) reverse transcriptase (Boehringer Mannheim Biochemicals) to synthesize cDNA. For PCR amplification, a forward primer that anneals to the 5'-untranslated region (5'-GACCCACCGCGCTCAAGCTCGGCTG-3') and a reverse primer that anneals to the $3^{\prime}$-end of the coding region of exon 2 (5'-AACAGGATGTGAATGTCTTCCAGAA-3') of the rat somatostatin gene
(60) were used. PCR conditions were: $95 \mathrm{C}$ for $5 \mathrm{~min}$, followed by 30 cycles of $94 \mathrm{C}$ for $30 \mathrm{sec}, 50 \mathrm{C}$ for $30 \mathrm{sec}$, and $72 \mathrm{C}$ for $1 \mathrm{~min}$, after which a 5-min incubation at $72 \mathrm{C}$ followed. After $\mathrm{PCR}$, an aliquot of the reaction was resolved in a $1 \%$ agarose gel, blotted onto a nylon membrane, probed with a ${ }^{32} \mathrm{P}-$ labeled internal primer that anneals to the $5^{\prime}$-region of exon 2 of the somatostatin gene (5'-TTCGAGTTGGCAGACCTCTGCAGCTCCAGCCT- $3^{\prime}$ ), and autoradiographed at $-70 \mathrm{C}$.

For immunocytochemistry, cells were plated into "LabTek" culture chambers (Nunc Inc., Naperville, IL), fixed in 4\% paraformaldehyde in PBS for $5 \mathrm{~min}$, washed in PBS, and permeabilized with methanol for $2 \mathrm{~min}$ at $-20 \mathrm{C}$. After blocking with normal goat serum, cells were incubated overnight with either normal rabbit serum or with a somatostatin-specific polyclonal antiserum (INCSTAR Co., Stillwater, MN) at 1:500 dilution. Immunodetection was carried out with a secondary biotinylated goat antirabbit antiserum (Bio-Rad Laboratories, Hercules, CA) using immunoperoxidase staining with a Vectastain ABC kit (Vector Laboratories, Burlingame, $\mathrm{CA})$.

For RIA, cells growing in 35-mm dishes were scraped in 2 $M$ acetic acid and boiled for $5 \mathrm{~min}$. After centrifugation, the supernatant was collected, adjusted to $\mathrm{pH} 7.5$, and lyophilized. Somatostatin content in these samples was determined by RIA using an antiserum (dilution 1:75,000) generated in sheep against synthetic somatostatin as described (61). For

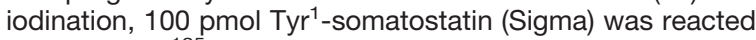
with $\left.1 \mathrm{mCi}{ }^{125} \mathrm{l}\right]$ sodium iodide (DuPont-New England Nuclear) using the method described by Greenwood et al. (62). The minimum detectable concentration was $7.8 \mathrm{pg} / \mathrm{ml}$.

\section{Western Immunoblots}

$\mathrm{RH} 1 . \mathrm{C} 4$ or RC2.E10 cells were plated in duplicate $35-\mathrm{mm}$ dishes at a density of $25 \times 10^{4}$ or $15 \times 10^{4}$ cells per dish, respectively. After an overnight incubation at $33 \mathrm{C}$, half of the plates were transferred to a $39 \mathrm{C}$ tissue culture incubator, and incubations at both $33 \mathrm{C}$ and $39 \mathrm{C}$ proceeded for an additional $24 \mathrm{~h}$. Cells were then lysed in buffer containing $125 \mathrm{~mm}$ Tris-HCl (pH 6.8), 4\% SDS, $15 \%$ glycerol, $10 \% \beta$-mercaptoethanol, and $10 \mathrm{~mm}$ dithiothreitol. Proteins were resolved by SDS-PAGE and blotted onto a nitrocellulose membrane. SV40T immunoreactivity was detected with a monoclonal primary antibody (1:1000 dilution) (Calbiochem, La Jolla, CA) and a horse antimouse peroxidase-conjugated secondary antibody (1:5000 dilution) (Bio-Rad). CREB immunoreactivity was detected with a polyclonal primary antiserum (1:500 dilution) (Santa Cruz Biotechnology, Santa Cruz, CA) and a goat antirabbit peroxidase-conjugated secondary antibody (1:20,000 dilution) (Bio-Rad). Immunoreactive bands were visualized using an enhanced chemiluminescence detection system (Amersham, Buckinghamshire, U.K.).

\section{Plasmid Constructions}

The plasmid SMS550 was constructed using DNA fragments obtained by PCR amplification of somatostatin gene sequences in the plasmid SMS900 (4). The upstream amplimers incorporated a $\mathrm{BamHI}$ restriction site in its $5^{\prime}$-end. The downstream amplimer annealed to the sequence corresponding to the Xbal site at position +54 . The resulting fragment was digested with the appropriate restriction enzymes, purified on an agarose gel, and ligated into the promoterless plasmid pOCAT (63) that had been digested with $\mathrm{BamHI}$ and Xbal. All other CAT reporter plasmids bearing $5^{\prime}$-deletions of the somatostatin promoter have been described previously $(4,5)$.

The plasmid SMS900 $\Delta$ CRE was constructed by ligating a $\mathrm{BamHI}-\mathrm{Bg} / \mathrm{ll}$ fragment obtained from SMS900 into the BamHI site of plasmid SMS65 $\triangle$ CRE (5). The resulting plasmid, SMS900 $\Delta$ CRE, preserves all the somatostatin gene sequences from positions -900 to +54 , with the exception of a 4-base deletion within the core CRE motif. 
Plasmids SMS900T1M, SMS900T2M, and SMS900UEBM have been described previously (8). Plasmid SMS900T3M was constructed by oligonucleotide-directed mutagenesis using a DNA fragment obtained by PCR amplification of somatostatin sequences in plasmid SMS900. The upstream amplimer anneals to a sequence located immediately upstream of the BamHI site of SMS900. The downstream amplimer was designed to anneal to a region of the somatostatin promoter spanning nucleotides -377 to -341 , which contains the SMS-TAAT3 sequence located upstream of a Kpnl site. This primer contained a six-base mismatch to replace

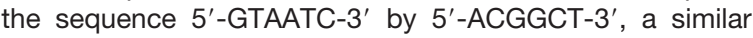
change to the ones introduced in SMS-TAAT1, SMS-TAAT2, and SMS-UE-B (8). Reduced binding of nuclear proteins to the mutated SMS-TAAT3 sequence was confirmed by EMSA using synthetic oligonucleotides (data not shown). After PCR amplification and restriction enzyme digestion, this fragment was used to replace the wild-type fragment located between $B a m H I$ and Kpnl in SMS900.

For the construction of T3SMS65, a synthetic doublestranded oligonucleotide corresponding to SMS-TAAT3 (nucleotides -377 to -355 ) with $\mathrm{BamHI}$ and $\mathrm{Bg} / \mathrm{ll}$ sites at the $5^{\prime}$ and $3^{\prime}$-ends, respectively, was ligated into the BamHI site of the plasmid SMS65 (4). The sequence of this oligonucleotide is (coding strand): $5^{\prime}$-GATCCAAGTCCAGTAATCTGAGTACAT-3'.

The correct sequence of all the newly made plasmids was verified by the enzymatic procedure (Sequenase, United States Biochemical Corp., Cleveland, $\mathrm{OH}$ ).

\section{Transfections and CAT Assays}

Initially, DNA transfections of neural cells were tested using three different methodologies: a modified diethylaminoethyldextran procedure (5), a calcium phosphate-DNA coprecipitation method, and lipofectin (GIBCO Laboratories, Grand Island, NY). Two different CAT reporter plasmids were used in parallel experiments, one under the control of the $\beta$-actin promoter (a gift of Dr. William Walker, University of Pittsburgh), and another under the control of the Rous sarcoma virus (RSV) enhancer. The diethylaminoethyl-dextran procedure was found to yield very low levels of CAT activity and was discarded. The calcium phosphate-DNA coprecipitation method yielded adequate levels of reporter plasmid expression, and $\beta$-actin-CAT was found to exhibit levels of CAT activity higher than those of RSVCAT. However, the $\beta$-actinCAT/RSVCAT activity ratio was highly variable from experiment to experiment, a likely reflection that transfection efficiencies were not uniform. In contrast, when lipofectin was used, $\beta$-actin-CAT was consistently found to be 8 to 10 times more potent than RSVCAT (observed in at least five independent experiments carried out in duplicate). This information was used as an indication that transfection efficiencies were relatively uniform among different dishes in each experiment. This was confirmed in a different set of experiments in which cells were stained for $\beta$-galactosidase after transfection of a plasmid bearing an RSV- $\beta$-galactosidase fusion gene.

$\mathrm{RH} 1 . \mathrm{C} 4$ and RC2.E10 cells were transfected with lipofectin following instructions provided by the manufacturer. Cells growing as monolayers up to $80 \%$ confluency were trypsinized and plated at a density of $5 \times 10^{5}$ cells per $60-\mathrm{mm}$ plate. After an overnight incubation, $20 \mu \mathrm{g}$ of reporter plasmid DNA mixed with lipofectin were added to the cells in $1 \mathrm{ml}$ serum-free DMEM and incubated for $4 \mathrm{~h}$. After this, $3 \mathrm{ml}$ DMEM supplemented with $10 \%$ FBS was added. CAT activity was measured by a solution assay (64) $48 \mathrm{~h}$ after transfection. For CAMP-induction studies, 8-Br-cAMP was added to cells $16 \mathrm{~h}$ before harvesting. All the values are expressed as mean \pm SEM of at least three independent experiments carried out in duplicate.

\section{DNA Protein-Binding Assays}

EMSAs were carried out with nuclear extracts (65), in the presence of the protease inhibitors pepstatin A $(1 \mathrm{mg} / \mathrm{ml})$, leupeptin $(10 \mathrm{mg} / \mathrm{ml})$, aprotinin $(10 \mathrm{mg} / \mathrm{ml})$, and $p$-aminobenzamidine $(0.1 \mathrm{~mm})$. Protein concentrations were determined by the Bio-Rad protein assay with BSA as a standard. Synthetic complementary oligonucleotides with 5'-GATC overhangs were annealed and labeled by a fill-in reaction using $\alpha{ }^{32} \mathrm{P}-\mathrm{dATP}$ and Klenow enzyme. Binding reactions were carried out in the presence of $2 \mu \mathrm{g}$ of poly(deoxyinosinicdeoxycytidylic)acid, and specific competitors, as indicated, using nuclear extracts (10 $\mu \mathrm{g}$ protein) incubated with 20,000 $\mathrm{cpm}$ of radiolabeled probe $(\sim 6-10 \mathrm{fmol})$ in a total volume of $20 \mu$ l containing $20 \mathrm{~mm}$ potassium phosphate (pH 7.9), $70 \mathrm{~mm}$ $\mathrm{KCl}, 1 \mathrm{~mm}$ dithiothreitol, $0.3 \mathrm{~mm}$ EDTA, and $10 \%$ glycerol. The sequences of the oligonucleotides corresponding to SMSTAAT1, SMS-TAAT2, SMS-UE-B, and nonspecific competitor have been published previously (6-8). The sequence of the SMS-TAAT3 oligonucleotide is identical to the one used to construct the plasmid T3SMS65 (see above).

\section{Acknowledgments}

We thank Guillermina Almazan for retrovirus-producing $\Psi$-2 fibroblasts, Chris Miller and Joel Habener for plasmids and Hm-66 antiserum, Tim Kieffer and Karen McManus for help with somatostatin RIA, Patrick Sluss and Sheila Mallette for carrying out iodination of Tyr-somatostatin, and Mehboob Hussain, Joel Habener, and members of our laboratory for critical reading of the manuscript.

Received February 25, 1998. Revision received May 22, 1998. Accepted June 5, 1998.

Address requests for reprints to: Mario Vallejo, MD., Ph.D., Reproductive Endocrine Unit, Massachusetts General Hospital, BHX-516, 55 Fruit Street, Boston, Massachusetts 02114.

This work was supported in part by NIH Grant DK-49670 and by a grant from the Whitehall Foundation Inc. P.S. was supported by fellowships from the University of Hamburg (Germany) and from Deutsche Forschungsgemeinschaft.

\section{REFERENCES}

1. MacArthur L, Eiden L 1996 Neuropeptide genes: targets of activity-dependent signal transduction. Peptides $17: 721-728$

2. Reichlin S 1983 Somatostatin. N Engl J Med 309: 1495-1501

3. Montminy MR, Sevarino KA, Wagner JA, Mandel G, Goodman RH 1986 Identification of a cyclic-AMPresponsive element within the rat somatostatin gene. Proc Natl Acad Sci USA 8:6682-6686

4. Powers AC, Tedeschi F, Wright KE, Chan JS, Habener JF 1989 Somatostatin gene expression in pancreatic islet cells is directed by cell-specific DNA control elements and DNA-binding proteins. J Biol Chem 264: 10048-10056

5. Vallejo M, Miller CP, Habener JF 1992a Somatostatin gene transcription regulated by a bipartite pancreatic islet D-cell-specific enhancer coupled synergetically to a cAMP response element. J Biol Chem 267:12868-12875

6. Vallejo M, Gosse M, Beckman W, Habener JF 1995 Impaired cyclic AMP-dependent phosphorylation renders CREB a repressor of C/EBP-induced transcription of the somatostatin gene. Mol Cell Biol 15:415-424 
7. Vallejo M, Penchuk L, Habener JF 1992b Somatostatin gene upstream enhancer element activated by a protein complex consisting of CREB, Isl-1-like, and $\alpha$-CBF-like transcription factors. J Biol Chem 267:12876-12884

8. Miller CP, McGehee RE, Habener JF 1994 IDX-1: a new homeodomain transcription factor expressed in rat pancreatic islets and duodenum that transactivates the somatostatin gene. EMBO J 13:1145-1156

9. Leonard J, Peers B, Johnson T, Ferreri K, Lee S, Montminy M 1993 Characterization of somatostatin transactivating factor-1, a novel homeobox factor that stimulates somatostatin expression in pancreatic islet cells. Mol Endocrinol 7:1275-1283

10. Vallejo M, Miller CP, Beckman W, Habener JF 1995 Repression of somatostatin gene transcription mediated by two promoter silencer elements. Mol Cell Endocrinol 113:61-72

11. Epelbaum J, Dournaud P, Fodor M, Viollet C 1994 The neurobiology of somatostatin. Crit Rev Neurobiol 8:25-44

12. Shiosaka S, Takatsuki K, Sakanaka M, Inagaki S, Takagi S, Senba E, Kawal Y, lida H, Minagawa H, Hara Y, Matsuzaki T, Tohyama M 1982 Ontogeny of somatostatincontaining neuron system of the rat: immunohistochemical analysis. II. Forebrain and diencephalon. J Comp Neurol 204:211-224

13. Burgunder J 1994 Ontogeny of somatostatin gene expression in rat forebrain. Dev Brain Res 78:109-122

14. Kungel M, Piechotta K, Rietzel H, Friauf E 1997 Influence of the neuropeptide somatostatin on the development of dendritic morphology: a cysteamine-depletion study in the rat auditory brainstem. Dev Brain Res 101:107-114

15. Davidson K, Gillies G 1993 Neuronal vs. glial somatostatin in the hypothalamus: a cell culture study of the ontogenesis of cellular location, content and release. Brain Res 624:75-84

16. Almazan G, Lefebvre D, Zingg H 1989 Ontogeny of hypothalamic vasopressin, oxytocin and somatostatin gene expression. Dev Brain Res 45:69-75

17. Almazan G, McKay R 1992 An oligodendrocyte precursor cell line from rat optic nerve. Brain Res 579:234-245

18. Frederiksen K, Jat PS, Valtz N, Levy D, McKay R 1988 Immortalization of precursor cells from the mammalian CNS. Neuron 1:439-448

19. Perez-Villamil B, McManus $M$, Schwartz $P$, Vallejo $M$, Cortical astrocyte precursor cells express Opx-1, an Otxand Pax-related homeoprotein developmentally regulated in the forebrain. Program of the 27th Annual Meeting of the Society for Neuroscience, New Orleans, LA, 1997, p 299 (Abstract)

20. Peers B, Sharma S, TJ, Kamps M, Montminy M 1995 The pancreatic islet factor STF-1 binds cooperatively with $\mathrm{Pbx}$ to a regulatory element in the somatostatin promoter: importance of the FPWMK motif and of the homeodomain. Mol Cell Biol 15:7091-7097

21. Leonard J, Serup P, Gonzalez G, Edlund T, Montminy M 1992 The LIM family transcription factor Isl-1 requires cAMP response element binding protein to promote somatostatin expression in pancreatic islet cells. Proc Natl Acad Sci USA 89:6247-6251

22. Andrisani OM, Pot DA, Zhu Z, Dixon JE 1988 Three sequence-specific DNA-protein complexes are formed with the same promoter element essential for expression of the rat somatostatin gene. Mol Cell Biol 8:1947-1956

23. Mori N, Stein R, Sigmund O, Anderson D 1990 A cell type-preferred silencer element that controls the neural specific expression of the SCG10 gene. Neuron 4:583-594

24. Li L, Suzuki T, Mori N, Greengard P 1993 Identification of a functional silencer element involved in neuron-specific expression of the synapsin I gene. Proc Natl Acad Sci USA 90:1460-1464

25. Kraner SD, Chong JA, Tsay HJ, Mandel G 1992 Silencing the type II sodium channel gene: a model for neuralspecific gene regulation. Neuron 9:37-44

26. Wood I, Roopra A, Buckley N 1996 Neural specific expression of the $\mathrm{m} 4$ muscarinic acetylcholine receptor gene is mediated by a RE1/NRSE-type silencing element. J Biol Chem 271:14221-14225

27. Lonnenberg $P$, Schoenherr $C$, Anderson D, Ibañez C 1996 Cell type-specific regulation of choline acetyltransferase gene expression: role of the neuron-restrictive silencer element and cholinergic-specific enhancer sequences. J Biol Chem 271:33358-33365

28. Timmusk T, Palm K, Metsis M, Reintam T, Paalme V, Saarma M, Persson H 1993 Multiple promoters direct tissue-specific expression of the rat BDNF gene. Neuron 10:475-489

29. Bessis A, Champtiaux N, Chatelin L, Changeux J 1997 The neuron-restrictive silencer element: a dual enhancer/ silencer crucial for patterned expression of a nicotinic gene in the brain. Proc Natl Acad Sci USA 94:5906-5911

30. Schoenherr CJ, Anderson DJ 1995 The neuron-restrictive silencer factor (NRSF): a coordinate repressor of multiple neuron-specific genes. Science 267:1360-1363

31. Chong J, Tapia-Ramirez J, Kim S, Toledo-Aral J, Zheng Y, Boutros MC, Altshuller YM, Frohman MA, Kraner SD, Mandel G 1995 REST: a mammalian silencer protein that restricts sodium channel gene expression to neurons. Cell 80:949-957

32. Atouf F, Czernichow P, Scharfmann R 1997 Expression of neuronal traits in pancreatic beta cells: implication of neuron-restrictive silencing factor/repressor element silencing transcription factor, a neuron-restrictive silencer. J Biol Chem 272:1929-1934

33. Simon C 1995 Gotta have GATA. Nat Genet 11:9-11

34. Redmond L, Hockfield S, Morabito M 1996 The divergent homeobox gene PBX1 is expressed in the postnatal subventricular zone and interneurons of the olfactory bulb. J Neurosci 16:2972-2982

35. Thor S, Ericson J, Brannstrom T, Edlund T 1991 The homeodomain LIM protein Isl-1 is expressed in subsets of neurons and endocrine cells in the adult rat. Neuron $7: 881-889$

36. Turque N, Plaza S, Radvanyi F, Carriere C, Saule S 1994 Pax-QNR/Pax-6, a paired box- and homeobox-containing gene expressed in neurons, is also expressed in pancreatic endocrine cells. Mol Endocrinol 8:929-938

37. Hussain M, Lee J, Miller C, Habener J 1997 POU domain transcription factor brain-4 confers pancreatic $\alpha$-cellspecific expression of the proglucagon gene through interaction with a novel proximal promoter G1 element. Mol Cell Biol 17:7186-7194

38. Sander M, Neubuser A, Kalamaras J, Ee H, Martin G, German M 1997 Genetic analysis reveals that PAX6 is required for normal transcription of pancreatic hormone genes and islet development. Genes Dev 11:1662-1673

39. Schwartz P, Perez-Villamil B, Vallejo M, Expression of IDX-1 (PDX-1) in neural precursor cells from developing forebrain. Program of the 79th Annual Meeting of The Endocrine Society, Minneapolis, MN, 1997, p 564 (Abstract)

40. Morris P, Dawson S, Wilson M, Latchman D 1997 A single residue within the homeodomain of the Brn-3 POU family transcription factors determines whether they activate or repress the SNAP-25 promoter. Neuroreport 8:2041-2045

41. Kallunki P, Jenkinson S, Edelman G, Jones F 1995 Silencer elements modulate the expression of the gene for the neuron-glia cell adhesion molecule, Ng-CAM. J Biol Chem 270:21291-21298

42. Quaggin S, Vanden-Heuvel G, Golden K, Bodmer R, Igarashi P 1996 Primary structure, neural-specific expression, and chromosomal localization of Cux-2, a second murine homeobox gene related to drosophila cut. J Biol Chem 271:22624-22634 
43. Jones F, Kioussi C, Copertino D, Kallunki P, Holst B, Edelman G 1997 Barx2, a new homeobox gene of the Bar class, is expressed in neural and craniofacial structures during development. Proc Natl Acad Sci USA 94:2632-2637

44. Hassan B, Li L, Bremer K, Chang W, Pinsonneault J, Vaessin H 1997 Prospero is a panneuronal transcription factor that modulates homeodomain protein activity. Proc Natl Acad Sci USA 94:10991-10996

45. Komuro I, Schalling M, Jahn L, Bodmer R, Jenkins N, Copeland N, Izumo S 1993 Gtx: a novel murine homeobox-containing gene, expressed specifically in glial cells of the brain and germ cells of testis, has a transcriptional repressor activity in vitro for a seruminducible promoter. EMBO J 12:1387-1401

46. Schnabel C, Abate-Shen C 1996 Repression by HoxA7 is mediated by the homeodomain and the modulatory action of its N-terminal-arm residues. Mol Cell Biol 16:2678-2688

47. Wu G, Lai E, Huang N, Wen X 1997 Oct-1 and CCAAT/ enhancer-binding protein (C/EBP) bind to overlapping elements within the interleukin-8 promoter. The role of Oct-1 as a transcriptional repressor. J Biol Chem 272:2396-2403

48. Lee S, Nagy B, Brooks A, Wang D, Paulweber B, LevyWilson B 1996 Members of the caudal family of homeodomain proteins repress transcription from the human apolipoprotein B promoter in intestinal cells. J Biol Chem 271:707-718

49. Briata P, llengo C, Van DeWerken R, Corte G 1997 Mapping of a potent transcriptional repression region of the human homeodomain protein EVX1. FEBS Lett 402:131-135

50. Smith S, Jaynes J 1996 A conserved region of engrailed, shared among all en-, gsc-, Nk1-, Nk2- and msh-class homeoproteins, mediates active transcriptional repression in vivo. Development 122:3141-3150

51. Chalepakis G, Jones F, Edelman G, Gruss P 1994 Pax-3 contains domains for transcription activation and transcription inhibition. Proc Natl Acad Sci USA 91:12745-12749

52. Dawson S, Morris P, Latchman D 1996 A single amino acid change converts an inhibitory transcription factor into an activator. J Biol Chem 271:11631-11633

53. Phelan M, Sadoul R, Featherstone M 1994 Functional differences between HOX proteins conferred by two residues in the homeodomain N-terminal arm. Mol Cell Biol 14:5066-5975

54. Roberts S, Green M 1995 Dichotomous regulators. Nature 375:105-106

55. Sauer F, Hansen S, Tjian R 1995 DNA template and activator-coactivator requirements for transcriptional synergism by Drosophila bicoid. Science 270:1825-1828

56. Moonkyoung U, Li C, Manley J 1995 The transcriptional repressor even-skipped interacts directly with TATAbinding protein. Mol Cell Biol 15:5007-5016

57. Hanna-Rose W, Hansen U 1996 Active repression mechanisms of eukaryotic transcription repressors. Trends Genet 12:229-234

58. Banker GA, Cowan WM 1977 Rat hippocampal neurons in dispersed cell culture. Brain Res 126:397-425

59. Philippe J, Chick WL, Habener JF 1987 Multipotential phenotypic expression of genes encoding peptide hormones in rat insulinoma cell lines. J Clin Invest 79:351-358

60. Montminy MR, Goodman RH, Horovitch SJ, Habener JF 1984 Primary structure of the gene encoding rat preprosomatostatin. Proc Natl Acad Sci USA 81:3337-3340

61. Seal A, Yamada T, Debas H, Hollinshead J, Osadchey B, Aponte G, Walsh J 1982 Somatostatin-14 and -28: clearance and potency on gastric function in dogs. Am J Physiol 243:G97-G102

62. Greenwood R, Hunter W, Grover J 1963 The preparation of ${ }^{131}$ I-labelled human growth hormone of high specific radioactivity. Biochem J 89:114-120

63. Prost E, Moore DD 1986 CAT vectors for analysis of eukaryotic promoters and enhancers. Gene 45:107-111

64. Seed B, Sheen JY 1988 A simple phase-extraction assay for chloramphenicol acetyltransferase activity. Gene 67:271-277

65. Schreiber E, Matthias P, Müller MM, Schaftner W 1989 Rapid detection of octamer binding proteins with miniextracts prepared from a small number of cells. Nucleic Acids Res 17:6419 